\title{
ALTERAÇÕES IMUNOLÓGICAS NA ICTERÍCIA OBSTRUTIVA
}

\author{
IMMUNOLOGICAL ALTERATIONS IN OBSTRUCTIVE JAUNDICE
}

Ajith K. Sankarankutty ${ }^{1}$, Carlos Augusto Teixeira da Cruz², Rubens G. Granato ${ }^{3}$, Luiz A. G. Menegazzo ${ }^{3}$ \& Orlando de Castro e Silva Jr. ${ }^{4}$

Aluno do curso de Pós-Graduação do Departamento de Cirurgia, Ortopedia e Traumatologia'; ${ }^{1}$ Docente ${ }^{2}$; Aluno do Curso de Graduação ${ }^{3}$; Docente e Coordenador do Núcleo de Pesquisas em Hepatologia Cirúrgica do Setor de Cirurgia Experimental do Departamento de Cirurgia $^{4}$ da Faculdade de Medicina de Ribeirão Preto da Universidade de São Paulo.

CoRRESPONDÊNCIA: Ajith K Sankarankutty - Departamento de Cirurgia, Ortopedia e Traumatologia da Faculdade de Medicina de Ribeirão Preto - Campus Universitário - CEP: 14048-900 - Ribeirão Preto - SP. E-mail: ajiths@netsite.com.br.

SANKARANKUTTY, AK et al. Alterações imunológicas na icterícia obstrutiva. Medicina, Ribeirão Preto, 30: 183-191, abr./jun. 1997.

RESUMO: Pacientes com icterícia obstrutiva apresentam maior índice de complicações perioperatórias, dentre as quais uma das principais é a sepsis. Parece que existe depressão do sistema imune nesses pacientes, decorrente de múltiplos fatores, entre eles a endotoxemia. Neste artigo, estão abordadas as alterações imunológicas encontradas na obstrução biliar, sob três aspectos: (i) a ausência de bile na luz intestinal, (ii) a obstrução do fluxo biliar e (iii) o acúmulo de substâncias tóxicas. Cuidados intensivos perioperatórios têm permitido a redução da mortalidade nas últimas décadas, mas estratégias para reduzir a morbidade continuam sendo estudadas.

UNITERMOS: Colestasia. Sistema Imune. Endotoxinas.

A icterícia obstrutiva é uma manifestação freqüente de doenças da via biliar extra-hepática. Apesar dos avanços nos cuidados perioperatórios, os procedimentos cirúrgicos nestes pacientes estão associados a maiores índices de complicações em comparação com cirurgias similares em pacientes sem icterícia ${ }^{1,2}$. Em centros especializados, enquanto que a mortalidade pós-operatória de cirurgias biliares de grande porte tem diminuído de aproximadamente $20 \%$ para $5 \%$, os índices de morbidade têm permanecido os mesmos, variando de $20 \%$ a $70 \% 1,3$. As complicações mais comuns são a sepsis, as hemorragias, os distúrbios renais e de coagulação ${ }^{1,2}$. A elevada incidência de complicações sépticas sugere um comprometimento do sistema de defesa nesse grupo de pacientes.
Os distúrbios imunológicos provocados pela icterícia obstrutiva podem ser analisados sob três aspectos, muitas vezes interrelacionados:

1 - ausência de bile na luz intestinal

2 - obstrução do fluxo biliar

3 - acúmulo de substâncias tóxicas

\section{1 - AUSÊNCIA DE BILE NA LUZ INTESTINAL}

Na icterícia obstrutiva, existe maior incidência de translocação bacteriana, endotoxemia e complicações infecciosas, induzidas pela ausência de bile na luz intestinal. A endotoxemia e a translocação bacteriana são consideradas alguns dos principais fatores responsáveis pelas alterações imunológicas encontradas na icterícia obstrutiva. 
$\mathrm{Na}$ icterícia obstrutiva, a associação entre a endotoxemia pré-operatória e a mortalidade pós-operatória é significativa ${ }^{1}$. Normalmente, apenas quantidades mínimas de endotoxina, o constituinte lipopolissacarídeo da parede celular das bactérias gram- negativas, são absorvidas do trato digestivo. A endotoxemia tem sido documentada em várias situações clínicas, como nos choques hemorrágicos, nas queimaduras extensas, na desnutrição protéica e na icterícia obstrutiva $^{4}$. O aumento da absorção de endotoxina nos pacientes ictéricos parece ser causado pela ausência de sais biliares na luz intestinal ${ }^{1}$. Inicialmente (primeira semana de icterícia obstrutiva) existe um aumento na capacidade de depuração das endotoxinas derivadas do território portal, pelas células de Kupffer, provavelmente estimuladas pela própria endotoxina. A endotoxemia portal (38 - 67\%) é maior que a endotoxemia sistêmica (35 - 45\%) nessa fase inicial. Com a persistência da obstrução biliar, existe uma depressão da depuração pelas células de Kupffer, resultando no 'extravasamento' das endotoxinas para a circulação sistêmica'.

O processo de migração de bactérias entéricas através da barreira mucosa intestinal até os linfonodos mesentéricos, orgãos e tecidos remotos é chamado de translocação bacteriana. $O$ intestino contém uma enorme quantidade de endotoxinas e bactérias viáveis, potencialmente patogênicas, da qual somente uma fração é suficiente para matar o hospedeiro. Esse processo está implicado na resposta inflamatória sistêmica ao trauma,ao choque hipovolêmico,às queimaduras, nutrição parenteral e icterícia obstrutiva ${ }^{6}$. $\mathrm{Na}$ icterícia obstrutiva, a ausência de bile na luz intestinal parece ser um fator importante que favorece a translocação bacteriana. Wells et al. ${ }^{7}$ demonstraram, no seu estudo, que a bile inibe a endocitose de bactérias pelos enterócitos. No entanto, para observar esse efeito inibitório, não basta apenas o contato por um curto período de tempo, pois as bactérias precisam ser cultivadas em meio contendo bile.

Num estudo, envolvendo um grupo de ratos livres de bactérias e outro grupo de ratos convencionais, foi avaliada a reatividade dos linfócitos esplênicos ao estímulo com mitógenos, duas semanas após a ligadura dos ductos biliares. Não foi encontrada endotoxina plasmática em nenhum dos grupos, mas não havia alterações na imunidade celular dos ratos livres de bactérias. A administração crônica de baixas doses de endotoxina a esse grupo de ratos provocou uma supressão da imunidade celular similar à dos ratos convencionais, mostrando, indiretamente, que deve ser a endotoxina a causa desse fenômeno ${ }^{8}$.

Mecanismos fisiológicos que previnem a translocação bacteriana incluem: i) colonização do intestino por organismos anaeróbios não-patogênicos (100 a 1000 vezes mais que outros organismos) previne outras bactérias de aderir à mucosa e reduz o supercrescimento bacteriano; alterações na composição da flora intestinal decorrentes do uso de antibióticos, da estase intestinal, ou dos distúrbios nutricionais, resultam em translocação; (ii) a camada de muco e a mucosa intestinal normalmente são barreiras eficientes, mas podem se tornar permeáveis devido a trauma direto aos enterócitos ou por fluxo sanguíneo reduzido ao intestino, como no choque hemorrágico e nas queimaduras, ou durante a nutrição parenteral total, na qual ocorre a atrofia da mucosa intestinal; (iii) durante a translocação, as bactérias podem escapar da fagocitose, quando existe uma depressão do sistema imunológico, como ocorre durante a quimioterapia e o uso de corticóides ${ }^{1}$. A imunoglobulina A (IgA) secretada na luz intestinal também pode servir de primeira linha de defesa contra a invasão de bactérias ${ }^{1}$. Em ratos, os níveis de Escherichia coli e de aeróbios no ceco são significativamente maiores após a ligadura do ducto biliar, quando comparados aos controles, embora não haja diferença na contagem total de bactérias ${ }^{1}$. A redução da motilidade intestinal na icterícia obstrutiva pela ausência de sais biliares, também pode ter um papel por favorecer o supercrescimento bacteriano. Mudanças na flora intestinal normal também podem ser provocadas pela própria endotoxemia ${ }^{4}$. O 'extravasamento' sistêmico das endotoxinas portais, por si, altera a integridade da mucosa intestinal, facilitando ainda mais a translocação bacteriana e mantendo o ciclo vicioso, perpetuando a resposta inflamatória séptica sistêmica ${ }^{4}$, sendo considerado por alguns como o 'motor' da insuficiência dos múltiplos orgãos e sistemas. Endotoxina, administrada em doses não letais, via intraperitoneal ou intramuscular, induz translocação bacteriana em até $80 \%$ dos linfonodos mesentéricos dos camundongos ${ }^{1}$. A hipoperfusão esplâncnica tem um papel importante na endotoxemia: com a redução da perfusão do íleo distal e ceco, aumenta a permeabilidade intestinal ${ }^{1}$.

Em resumo, existe evidência de que ocorre a translocação bacteriana na icterícia obstrutiva experimental, que resulta de mudanças na permeabilidade intestinal ou na composição da flora intestinal, e se acentua pela endotoxemia concomitante. 
Imunossupressão na Icterícia Obstrutiva: A icterícia obstrutiva afeta vários aspectos da função imunológica celular. As células de Kupffer constituem 80 a $90 \%$ do sistema fagocitário mononuclear e têm grande responsabilidade em eliminar partículas circulantes, como as endotoxinas, microorganismos derivados do trato digestivo, células mortas ou danificadas e debris teciduais ${ }^{1,9}$.

Normalmente, o sistema fagocitário mononuclear do fígado e baço se encarrega da remoção das bactérias circulantes (fígado $82 \%$, pulmão $4 \%$ e baço $12 \%$ ), mas na icterícia obstrutiva existe aumento na localização pulmonar das bactérias (fígado 66\%, pulmão $22 \%$ e baço $12 \%$ ) administradas via endovenosa em ratos ${ }^{10}$. Apesar da maior captação, a viabilidade das bactérias no pulmão é quinze a vinte vezes maior que das bactérias presentes no fígado, mostrando boa captação, porém capacidade reduzida de destruição das bactérias ${ }^{11}$. Essas bactérias viáveis podem ser responsáveis pela manutenção da resposta inflamatória.

A imunidade celular inespecífica extra-hepática é importante para controle e eliminação de bac- térias. Em estudos realizados na FMRP-USP, os macrófagos peritoneais de ratos com ligadura do ducto biliar demonstraram aumento na capacidade de fagocitose, mas redução da produção de peróxido de hidrogênio, sugerindo um déficit na lise intracelular ${ }^{12}$ (Figura 1 e 2). Outros estudos encontraram redução nas respostas metabólicas e da fagocitose mas que estavam associadas a maior produção espontânea e estimulada de citocinas ${ }^{1}$. Esse estado 'pro-inflamatório' não necessariamente resulta em maior destruição bacteriana.

Roughneen et al. demonstraram que a capacidade de migração dos polimorfonucleares (PMN) não foi afetada durante a colestase, mas a sua atividade fagocítica (do Staphylococcus aureus marcado) foi inibida. Nesse estudo, os PMN de animais colestáticos demonstraram aumento na liberação de superóxido ${ }^{13}$. O consenso geral é que existe comprometimento da imunidade célular extra-hepática, e as diferenças encontradas na literatura podem ser devidas aos tipos de células estudadas e ao tempo de obstrução biliar envolvido.

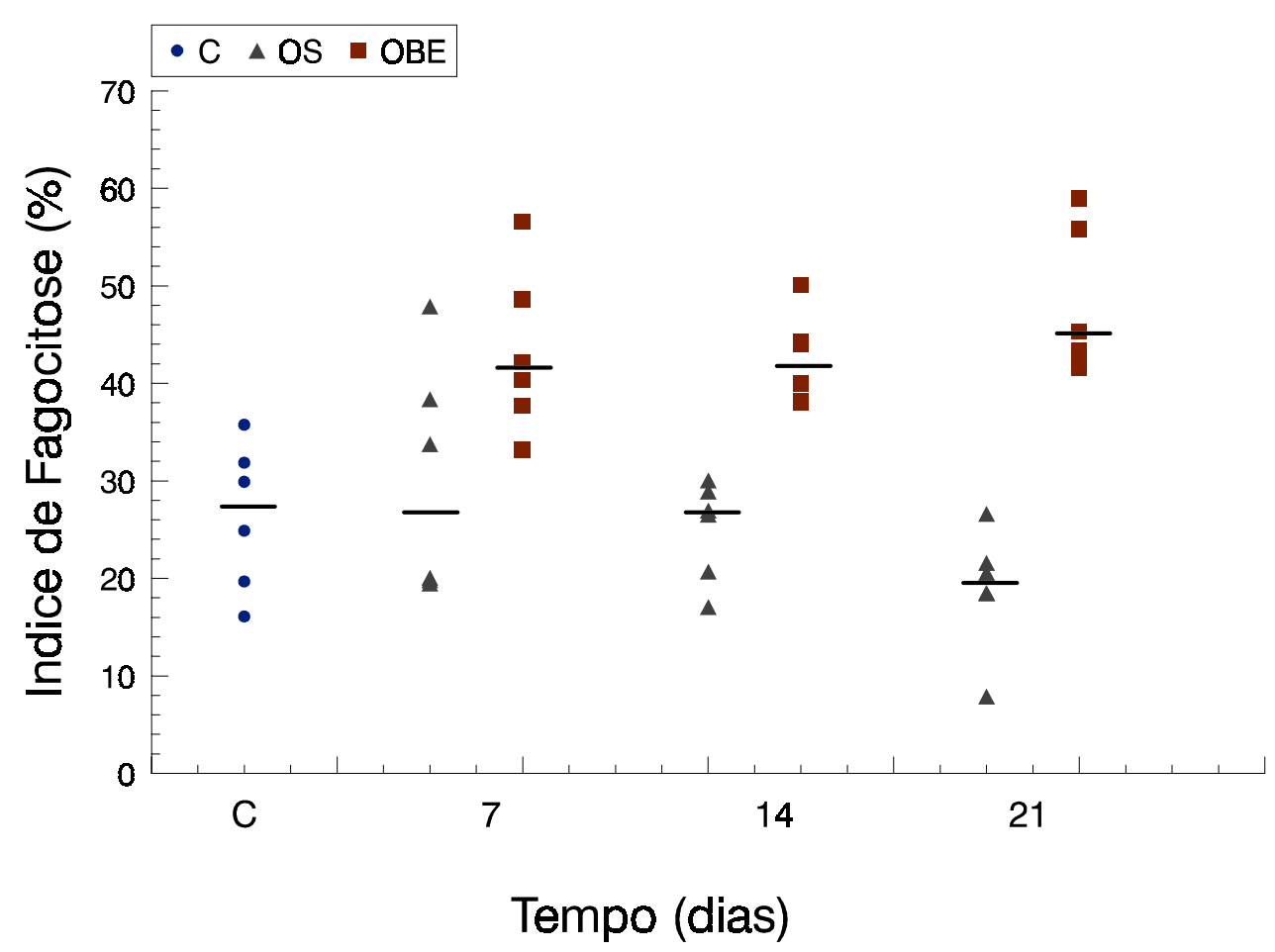

Figura 1 - Representação individual do índice de fagocitose. Foram utilizadas amostras de macrófagos de ratos submetidos a obstrução biliar (OBE) e operação simulada (OS) no sétimo, $14^{\circ}$ e $21^{\circ}$ dia após a operação e de seis ratos controle (C). 


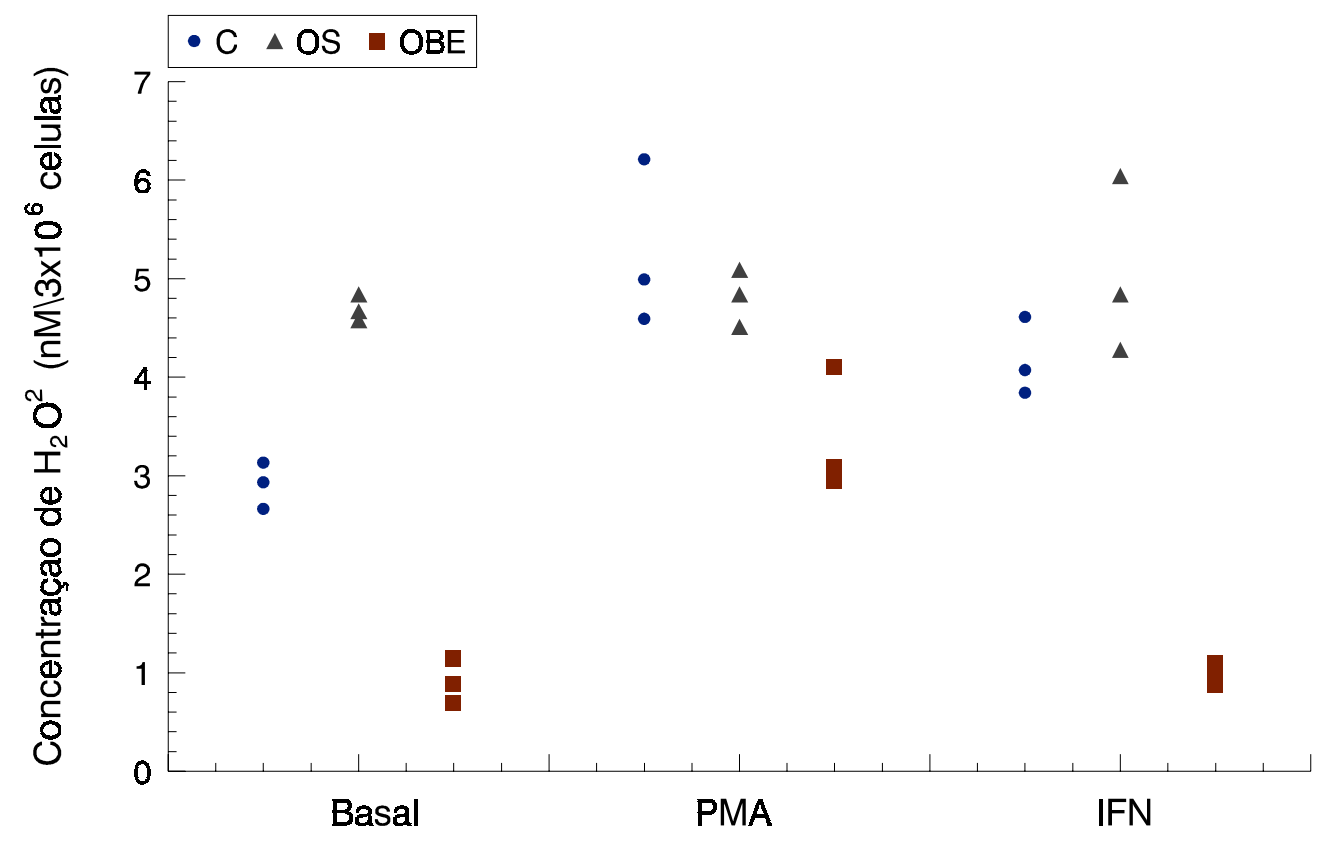

Figura 2 - Representação dos valores individuais obtidos com a avaliação da liberação de Peróxido de Hidrogênio $\left(\mathrm{nM} / 3 \times 10^{6}\right.$ células) por macrófagos da cavidade peritoneal de ratos dos diferentes grupos. Foram utilizados amostras de macrófagos de ratos dos grupos controle (C), OS (operação Simulada) e OBE (obstrução biliar extra-hepática) obtidos no $21^{\circ}$ dia de observação. Foram avaliadas a produção basal, e a estimulada após tratamento in vitro com Acetato de Miristato de Forbol (PMA - $100 \mathrm{ng} / \mathrm{ml}$ ) ou Interferon-gama (IFN - $100 \mathrm{U} / \mathrm{ml}$ ) por 45 minutos.

Um fator sérico inibidor do sistema imune tem sido estudado. Foi demonstrado que o soro de animais ictéricos tem efeito supressor sobre os linfócitos humanos ${ }^{1}$. Vários fatores, além da endotoxina, devem estar envolvidos, incluindo as deficiências nutricionais. A suplementação de L-arginina, um aminoácido semi-essencial, previne parcialmente a imunossupressão ${ }^{1}$.

Parece existir, portanto, depressão geral da imunidade mediada por células, na icterícia obstrutiva, que está relacionada à endotoxemia e provavelmente influenciada por outros fatores. Os mecanismos exatos da imunossupressão ainda não estão claros.

Citocinas na Icterícia Obstrutiva: Citocinas, proteínas proi-2nflamatórias produzidas por células imunocompetentes em resposta à vários estímulos, como por exemplo à endotoxina, exercem um papel importante nos processos inflamatórios.

Poucas citocinas têm sido estudadas na icterícia obstrutiva. O fator de necrose tumoral (TNF) é um mediador central em muitas respostas inflamatórias. Em modelos experimentais de obstrução biliar, os níveis de TNF aumentam. Também tem sido detectado TNF circulante em pacientes ictéricos ${ }^{1}$.

Dois receptores solúveis de TNF foram encontrados no soro e na urina de pessoas saudáveis, e são a parte extra-celular dos receptores nas membranas celulares. Eles são liberados das membranas em várias situações inflamatórias, como na endotoxemia experimental ${ }^{1}$ e parecem ter um papel na regulação do TNF. Vários outros estímulos, além do TNF, também causam a liberação dos receptores. Essa liberação pode representar um mecanismo de proteção do hospedeiro contra os efeitos deletérios do TNF através da sua ligação e inativação, além da perda dos receptores reduzir a responsividade das células ao TNF. Por outro lado, os receptores podem servir de reservatórios de liberação lenta, prolongando os efeitos do TNF.

A interleucina-6 (IL-6) é um importante regulador da resposta da fase aguda e sua concentração sérica aumenta bem mais rápido que a proteína $\mathrm{C}$ reativa, sendo útil para estimar o grau de trauma, 
inflamação e respostas do hospedeiro induzidas por endotoxina. A IL-6 está aumentada nos camundongos ictéricos quando comparados a camundongos submetidos à operação simulada ${ }^{1}$. Nos dois grupos de animais, o próprio procedimento cirúrgico induziu um aumento transitório nos níveis de IL-6, mas que retornou aos valores normais nos animais submetidos a operação simulada. Nos animais ictéricos, ocorre novo aumento nos níveis de IL-6 circulantes a partir do décimo segundo dia da ligadura do ducto biliar, indicando um estado pro-inflamatório mantido durante a icterícia obstrutiva.

Muitos outros mediadores inflamatórios devem estar envolvidos. 'Transforming Growth Factor- $\beta$ ' (TGF- $\beta$ ) é um fator de crescimento presente nas plaquetas e também liberado por diferentes células inflamatórias. Ele tem propriedades múltiplas, desde a imunossupressão até efeitos pro-inflamatórios potentes e controle da reparação tecidual e fibrose. Níveis elevados de TGF- $\beta$ foram encontrados nos pacientes ictéricos ${ }^{1}$.

Estudos in vitro demonstram que o Fator Ativador de Plaquetas (PAF) age como sinal intercelular nas interações celulares e também como mensageiro intracelular na liberação de eicosanóides e radicais livres. Ambos os mecanismos podem estar envolvidos nos modelos in vivo de fisiopatologia hepática. No fígado, as células de Kupffer são a principal fonte de PAF. Zhou et. al. mostraram que inicialmente (primeira semana) na obstrução biliar em ratos, a endotoxina estimula a produção de PAF pelas células de Kupffer, mas no final da segunda semana existe uma queda nos níveis de PAF, sugerindo depressão na função das células de Kupffer com conseqüente redução de $\mathrm{PAF}^{14}$. A produção endógena de PAF pelas células de Kupffer pode ser um evento intermediário que liga a obstrução biliar à inflamação hepática.

Portanto, várias citocinas estão envolvidas na resposta inflamatória à icterícia obstrutiva e é provavel que elas estejam envolvidas na morbidade desses pacientes.

\section{2 - OBSTRUÇÃO AO FLUXO BILIAR}

Castro e Silva Jr. encontrou uma redução no fluxo sanguíneo portal após ligadura do ducto biliar, em ratos, avaliada com o auxílio de fluxômetro eletromagnético, que resulta num estado de isquemia funcional do fígado. Após a descompressão biliar, aumenta o fluxo portal, mas mesmo assim permanece um pouco abaixo do grupo controle ${ }^{15}$. Alguns autores acreditam que a resolução da obstrução biliar, com conseqüente melhora da função dos hepatócitos e das células de Kupffer, é o fator mais importante na endotoxemia, e não a ausência da bile no intestino. Esses autores relatam que tanto a drenagem biliar interna como a externa revertem a endotoxemia ${ }^{16}$. Em estudo experimental, eles usaram a fístula coledocovesical como o modelo de drenagem biliar externa. Esse modelo evita complicações tais como fístula biliar, sangramento e sepsis pelo cateter, e pode explicar seus bons resultados. Por outro lado, alguns estudos mostraram que a ausência de bile na luz intestinal é a causa da translocação bacteriana, e não a obstrução em $\mathrm{si}^{1}$. Esses autores demonstraram que a translocação ocorre tanto com a ligadura simples do ducto biliar, como também no modelo que envolve a derivação biliar para a bexiga. Portanto, esse aspecto ainda permanece controverso.

\section{3 - ACÚMULO DE SUBSTÂNCIAS TÓXICAS}

A obstrução biliar resulta no acúmulo de substâncias que são normalmente excretadas pela via biliar. Tem sido demonstrado que existe comprometimento na produção de superóxido pelos macrófagos peritoneais de ratos, quando incubados com a bilirrubina ${ }^{12}$. Assim, o comprometimento da excreção biliar provavelmente leva à retenção sistêmica de substâncias tóxicas com os consequentes efeitos deletérios.

Swain et al. estudaram a aderência e migração dos neutrófilos, induzidas por estímulos pró-inflamatórios, usando microscopia intravital, em ratos submetidos a ligadura do ducto biliar ${ }^{17}$. Nesses animais, apesar de existir maior número de neutrófilos circulantes, essas células têm menor capacidade de aderir e migrar para as áreas de inflamação. Os dados desse estudo sugerem que a capacidade de adesão dos neutrófilos não está comprometida, mas que existe um fator plasmático durante a colestase que impede essa adesão. Embora esse fator não esteja identificado, os estudos apontam para uma glicoproteína termoestável. Os ácidos biliares são possíveis candidatos a esse fator, mesmo que a sua ação seja mediada por alguma outra substância. A Figura 3 resume a sequiência de eventos que segue a icterícia obstrutiva, levando à depressão imunológica. 


\section{Icterícia Obstrutiva}

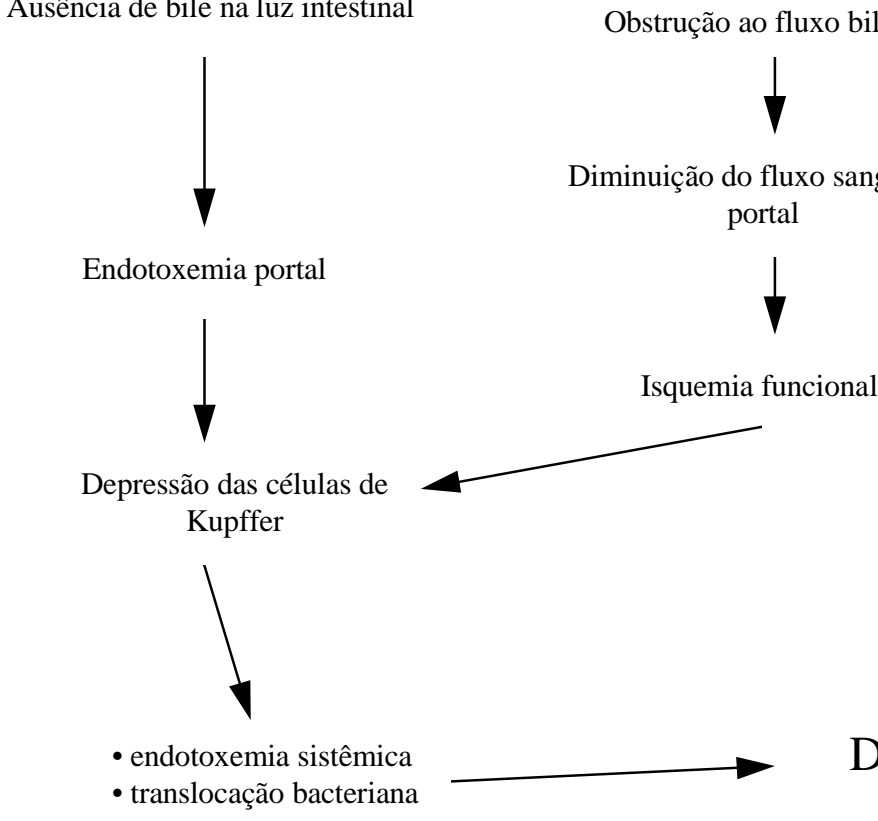

Depressão do Sistema Imune

Figura 3 - Icterícia obstrutiva: seqüência de eventos que levam a depressão imunológica.

\section{POSSIBILIDADES TERAPÊUTICAS PARA ABOR- DAGEM DE PACIENTES COM ICTERÍCIA OBS- TRUTIVA}

Várias estratégias estão sendo estudadas para reduzir a morbidade nos pacientes com icterícia obstrutiva. Em teoria, o melhor método seria a desobstrução biliar, retornando o fluxo de bile à luz intestinal, permitindo a eliminação de substâncias tóxicas, a secreção de fatores protetores e o restabelecimento do circuito fisiológico.

\section{Prevenção da Endotoxemia}

Diferentes métodos de redução dos níveis de endotoxinas ou de bactérias, no intestino, têm sido estudados na tentativa de prevenir as consequências da endotoxemia.

Drenagem Biliar Pré-operatória: a drenagem biliar interna pré-operatória, em teoria, restabeleceria o circuito fisiológico, mas a importância desse procedimento permanece controversa. Os autores japo- neses recomendam a drenagem biliar pré-operatória em todo paciente com níveis de bilirrubina total acima de $10 \mathrm{mg} / \mathrm{dl}$, principalmente nos pacientes a serem submetidos a ressecções hepáticas ${ }^{18}$. Por outro lado, autores ocidentais não recomendam a drenagem pré-operatória de rotina ${ }^{3}$, salvo em situações especiais enumeradas a seguir:

i) em pacientes com desnutrição grave, a associação de drenagem biliar pré-operatória e nutrição parenteral total diminuiu a morbidade e mortalidade de $47 \%$ e $13 \%$, respectivamente, para $18 \%$ e $4 \%$;

ii) nos 5 a $10 \%$ dos pacientes com colangite grave que não respondem ao tratamento conservador e que necessitam da descompressão da via biliar, a drenagem endoscópica tem menor morbidade (34\% versus $66 \%$ ) e mortalidade (10\% versus $30 \%$ ), quando comparada à drenagem cirúrgica. Tanto a drenagem percutânea como a endoscópica podem ser realizadas nesses casos, portanto a via depende da experiência de cada centro;

iii) a colocação de catéteres biliares, via percutânea, no pré-operatório, pode ajudar o cirurgião na 
dissecção do hilo hepático nos pacientes com comprometimento do trato biliar proximal, por exemplo, aqueles sendo submetidos à correção de estenose benigna das vias biliares ou então a ressecção de colangiocarcinoma peri-hilar. Esses catéteres podem ser usados para colocação de próteses durante a reconstrução ou mesmo como medida paleativa para tumores irressecáveis.

iv) pacientes a serem submetidos a ressecções hepáticas extensas por colangiocarcinoma peri-hilar, podem se beneficiar da colocação de catéteres (as vezes até múltiplos catéteres) para aliviar a icterícia e permitir a coledocoscopia percutânea para avaliar e mapear a extensão do tumor.

Em estudos experimentais, a drenagem biliar interna, que restabelece o fluxo biliar para o intestino, tem demonstrado uma melhora do estado nutricional, redução nos índices de mortalidade e redução significativa da endotoxemia sistêmica e portal, resultando em menor indução das citocinas ${ }^{1}$. Megison et. al. mostraram uma rápida recuperação da capacidade fagocítica hepática (7 dias) após a drenagem interna em $\operatorname{ratos}^{10}$. Apesar da normalização precoce dos parâmetros bioquímicos da função hepática, a reversão da disfunção das células T, após drenagem interna nos ratos, leva em torno de 28 dias ${ }^{19}$.

Embora os estudos experimentais mostrem melhora após drenagem interna, e apesar desta ser considerada um método fisiológico, as técnicas usadas para realizar a drenagem apresentam morbidade relacionada ao própio procedimento. No caso da drenagem biliar obtida pela punção percutânea transhepática $(\mathrm{PTH})$ da via biliar, as complicações incluem fístula biliar, sangramento, bacteriemia e abscessos hepáticos ${ }^{20,21}$. Parece que existe melhora na função renal e diminuição das complicações cirúrgicas nos pacientes submetidos à drenagem biliar interna, através de próteses introduzidas via percutânea, mas essas vantagens desaparecem quando se leva em conta a morbidade associada à colocação da prótese ${ }^{2}$. Lai et al. não encontraram diferenças na morbidade ou mortalidade entre os grupos submetidos à drenagem biliar endoscópica pré-operatória ou a exploração cirúrgica sem drenagem ${ }^{22}$.

Portanto não existe argumento definido para realizar a drenagem pré-operatória em todos os pacientes ictéricos, mas provavelmente um grupo seleto de pacientes com icterícia obstrutiva se beneficiará com a drenagem, como aqueles grupos mencionados acima.
LACTULOSE: um dissacarídeo sintético permanece praticamente inabsorvido no trato intestinal. Ele exerce uma carga osmótica dentro do intestino delgado, e ao chegar ao cólon, o metabolismo bacteriano reduz o pH intestinal, através da formação de ácidos carboxílicos. A acidez resultante aumenta a motilidade colônica que junto com o aumento da carga osmótica, constitui um dos principais mecanismos da ação laxativa. Em estudos in vitro, a lactulose provoca uma redução nos níveis de endotoxina, sugerindo um efeito antiendotoxina direto. Lactulose pode estar reduzindo a absorção de endotoxina pela redução ou alteração da flora intestinal, pelo efeito direto sobre a endotoxina ou então pelos dois mecanismos ${ }^{23}$. A lactulose também diminui a produção de TNF pelos monócitos, induzida pela endotoxina.

A administração oral pré-operatória de lactulose para pacientes com icterícia obstrutiva reduz a incidência de endotoxemia portal e sistêmica, diminuindo a incidência de disfunção renal. Sendo pequena a quantidade de lactulose absorvida do intestino, o seu efeito deve ser sobre a endotoxina da luz intestinal ${ }^{24}$.

SAis BiLiARES: são detergentes e inativam a molécula de endotoxina in vitro. Em estudos experimentais a absorção de endotoxina está aumentada na icterícia obstrutiva ou após a drenagem biliar externa, e reduzida se forem administrados sais biliares via oral ou realizada uma drenagem biliar interna. A escolha do sal parece ser importante. $\mathrm{O}$ deoxicolato de sódio tem a maior atividade detergente e o maior efeito antiendotóxico in vitro e in vivo. Em pacientes com icterícia obstrutiva, a administração oral de deoxicolato de sódio previne a endotoxemia portal e sistêmica e protege a função renal no período pós-operatório ${ }^{24}$. A capacidade dos sais biliares em reduzir a endotoxemia é de importância porque a endotoxemia em si, aumenta a permeabilidade intestinal e facilita a translocação bacteriana.

Colestiramina, Caolin e Pectin: são agentes que se ligam à endotoxina na luz intestinal. Na icterícia obstrutiva, esses seriam úteis e constituem uma modalidade terapêutica que necessita investigação ${ }^{25}$.

Antibióticos e Outras medidas: a lavagem intestinal reduz o número de bactérias na luz intestinal, e pode prevenir a endotoxemia em pacientes com doença inflamatória intestinal. Essa técnica provavelmente reduz a endotoxina disponível para absorção durante a icterícia obstrutiva, mas não é o que tem sido obser$\operatorname{vado}^{25}$. O uso de antibióticos orais não absorvíveis, 
não reduz de modo significativo a quantidade de endotoxina no intestino, com exceção da polimixina B. De fato, alguns antibióticos podem aumentar o conteúdo fecal de endotoxina pela liberação de LPS da parede celular ${ }^{25}$. A descontaminação seletiva do intestino com a polimixina e a tobramicina reduz a translocação bacteriana e a endotoxemia em ratos ${ }^{1}$.

Neutralização da Endotoxina: uma outra possibilidade terapêutica é a de ligar e neutralizar a endotoxina depois que tenha ocorrido a endotoxemia. Várias substâncias estão sendo investigadas, por exemplo, a polimixina $\mathrm{B}$ e os anticorpos antiendotoxina, devido aos seus efeitos antiendotóxicos diretos. Porém não há relatos de bons resultados. Esse insucesso deve ser, em parte, porque as medidas precisam ser adotadas precocemente, antes que a cascata de inflamação tenha progredido muito.

Enquanto se procuram meios de melhorar os índices de morbidade e mortalidade nos pacientes com icterícia obstrutiva, esses pacientes podem se beneficiar de cuidados intensivos perioperatórios, com atenção para a hidratação, para os distúrbios eletrolíticos e de coagulação, suporte nutricional, cobertura antibiótica, e técnica cirúrgica meticulosa e rápida.

SANKARANKUTTY, AK et al. Immunological alterations in obstructive jaundice. Medicina, Ribeirão Preto, 30: 183-191, apr./june 1997.

ABSTRACT: Patients with obstructive jaundice have a greater incidence of perioperative complications, especially sepsis. There seems to be a dysfunction of the immune system in these patients, due to various factors, including endotoxemia. This article deals with the immunologic effects, considering three aspects of the obstruction to the bile flow: (i) the absence of bile in the intestinal lumen, (ii) the mechanical obstruction of the bile flow and (iii) the acumulation of toxic substances. Adequate perioperative care has permitted a reduction in the mortality rates during the last decades, but strategies to reduce the morbidity continue to be studied.

UNITERMS: Cholestasis. Immune System. Endotoxins.

\section{REFERÊNCIAS BIBLIOGRÁFICAS}

1 - KIMMINGS $\mathrm{N}$ et al. Inflammatory and immunologic effects of obstructive jaundice: pathogenesis and treatment. Surg Gynecol Obstet 181: 567-581, 1995

2 - CLEMENTS WDB et al. Biliary drainage in obstructive jaundice: experimental and clinical aspects. Br J Surg 80: 834-842, 1993.

3 - NAKEEB A \& PITT HA. The role of preoperative biliary decompression in obstructive jaundice. Hepatogastroenterology 42: 332-337, 1995.

4 - CLEMENTS WDB et al. Role of the gut in the pathophysiology of extrahepatic biliary obstruction. Gut 39: 587-593, 1996.

5 - CLEMENTS WDB et al. Effects of extrahepatic obstructive jaundice on Kupffer cell clearance capacity. Arch Surg 128: 200-205, 1993.

6 - DING JW et al. Inhibition of bacterial translocation in obstructive jaundice by muramyl tripeptide phosphatidylethanolamine in the rat. J Hepatol 20: 720-728, 1994.
7 - WELLS CL, JECHOREK RP \& ERLANDSEN SL. Inhibitory effect of bile on bacterial invasion of enterocytes: Possible mechanism for increased translocation associated with obstructive jaundice. Crit Care Med 23: 301-307, 1995.

8 - GREVE JWM, GOUMA DJ \& BUURMAN WA. Complications in obstructive jaundice: Role of endotoxins. Scand J Gastroenterol 27: 8-12, 1992. Suppl. 194.

9 - DING JW et al. The influence of biliary obstruction and sepsis on reticuloendothelial function in rats. Eur $\mathbf{J}$ Surg 158: 157-164, 1992.

10 - MEGISON SM et al. Effects of relief of biliary obstruction on mononuclear phagocyte system function and cell mediated immunity. Br J Surg 78: 568-571, 1991.

11 - KATZ S et al. Impaired bacterial clearance and trapping in obstructive jaundice. Ann Surg 199: 14-20, 1984.

12 - CRUZ CAT. Aspectos funcionais de macrófagos na obstrução biliar extra-hepática experimental em ratos. Tese de Mestrado, Faculdade de Medicina de Ribeirão Preto da USP, Ribeirão Preto, p. 1-98, 1994. 
13 - ROUGHNEEN PT et al. Impaired nonspecific cellular immunity in experimental cholestasis. Ann Surg 206: 578-582, 1987.

14 - ZHOU W et al. Role of platelet-activating factor in hepatic responses after bile duct ligation in rats. Am J Physiol 263: G587-G592, 1992.

15 - CASTRO E SILVA JR O. Fluxo portal e atividade enzimática da piruvato quinase na obstrução biliar extra-hepática. Tese de Livre-Docência, Faculdade de Medicina de Ribeirão Preto da USP, Ribeirão Preto, p. 1-87, 1991.

16 - DIAMOND T et al. Development and reversal of endotoxemia and endotoxin-related death in obstructive jaundice. Surgery 108: 370-375, 1990.

17 - SWAIN MG et al. Neutrophil adhesion is impaired in a rat model of cholestasis. Gastroenterology 109: 923-932, 1995.

18 - KAWARADA $Y$ et al. Preoperative biliary drainage in obstructive jaundice. Hepatogastroenterology 42: 300-307, 1995.
19 - THOMPSON RLE et al. Development and reversibility of T lymphocyte dysfunction in experimental obstructive jaundice. Br J Surg 77: 1229-1232, 1990.

20 - DOOLEY JS et al. Relief of bileduct obstruction by the percutaneous transhepatic insertion of an endoprosthesis. Clin Radiol 32: 163-172, 1981

21 - STAMBUK EC et al. Percutaneous transhepatic drainage Risks and benefits. Arch Surg 118: 1388-1394, 1983.

22 - LAI ECS et al. Preoperative endoscopic drinage for malignant obstructive jaundice. Br J Surg 81: 1195-1198, 1994.

23 - PAIN JA \& BAILEY ME. Experimental and clinical study of lactulose in obstructive jaundice. Br J Surg 73: 775-778, 1986.

24 - PAIN JA et al. Prevention of postoperative renal dysfunction in patients with obstructive jaundice: a multicentre study of bile salts and lactulose. Br J Surg 78: 467-469, 1991.

25 - PAIN JA; CAHILL CJ \& BAILEY ME. Perioperative complications in obstructive jaundice: therapeutic considerations. Br J Surg 72: 942-945, 1985. 